\title{
PMR CHARACTERIZATION OF THE WATER STRUCTURE IN TIBETAN MILK MUSHROOM ZOOGLEA: INFLUENCE OF MEDIUM HYDRATION AND HYDROPHOBICITY
}

\author{
T. V. Krupskaya, ${ }^{a}$ Yu. I. Prylutskyy, ${ }^{b}$ M. P. Evstigneev,,${ }^{c, d^{*}}$ \\ M. D. Tsapko, ${ }^{a}$ and V. V. Turov ${ }^{a}$
}

UDC 539.143.43:620.3

The state of water in Tibetan milk mushroom zooglea with different degrees of hydration (h) was investigated using low-temperature PMR spectroscopy in air and in contact with the hydrophobic media polydimethylsiloxane PDMS-1000 and $\mathrm{CHCl}_{3}$ with added trifluoroacetic acid (TFA). The maximum hydration of the zooglea amounted to $h=32 \mathrm{~g} / \mathrm{g}$ (of dry matter). Water existed as polyassociates (clusters or domains) of strongly and weakly associated water. Bound water decomposed into clusters in the presence of TFA. The NMR spectra showed six types of bound water at $h=0.3 \mathrm{~g} / \mathrm{g}$.

Keywords: Tibetan milk mushroom zooglea, bound water, water domains, silicone.

Introduction. Zoogleae comprise microbial colonies that are characterized by functionally specialized cell components. The symbiont cells offer several advantages for coexistence such as an increased resistance to antibacterial agents and more effective use of growth substrates, especially in spatially limited ecological niches including a multi-celled animal (plant) as a host [1]. Colonies develop a complicated system of supracellular formations and microcavities formed by the mucous matrix and separated by open channels (often filled with water). This is its own analog of a primitive circulatory system that supplies growth substrates and eliminates metabolic products [2]. Intercellular interactions involving water forming the cell hydration shell and the supracellular matrix can be the driving force for functional differentiation in colonies. Interfacial interactions in biological systems were first examined by Kasemo [3].

A typical zooglea is the Tibetan milk mushroom, which is widely used as a drug to treat and prevent various diseases. Herein, it is used as a model to explore the state of water in cellular structures of microbial colonies.

Low-temperature PMR spectroscopy is an effective method for studying the state of bound water in cellular and supracellular systems [4-9]. The concentration of unfreezing water can be determined from the resonance intensity change in the range 200-273 K. The degree of its association can be estimated from the chemical shift. Assuming that the linear dimensions of intracellular water polyassociates control the freezing (thawing), the intracellular water cluster (nanodrops, domains) radius size distribution can be calculated from the concentration change of unfreezing water as a function of the freezing-point depression. The chemical shifts of an acid in the molecular components are greater than in free water. Therefore, water associates capable of dissolving a significant amount of acid can be detected by the presence of well resolved proton resonances in the presence of an acid. The present work was based on all these assumptions.

Experimental. A culture of milk symbiont that was grown during fermentation of whole milk was used. The cell mass was rinsed during sample preparation by a large volume of distilled water, placed on filter paper, and dried under normal conditions for $1 \mathrm{~h}$. The amount of water in the sample was determined gravimetrically by storing at $380 \mathrm{~K}$ for $1 \mathrm{~h}$ and showed that the dry cell mass made up 3 mass\%. NMR measurements were made in standard 5-mm tubes. PDMS-1000 (Oxane 1000, Bausch \& Lomb, USA) was used. A weighed portion of symbiont was mixed with the required amount of silicone and stirred thoroughly until the mixture was as homogeneous as possible.

*To whom correspondence should be addressed.

${ }^{\mathrm{a}}$ A. A. Chuiko Institute of Surface Chemistry, National Academy of Sciences of Ukraine, Kyiv, Ukraine; ${ }^{\mathrm{b}}$ Taras Shevchenko National University of Kyiv, Ukraine; ${ }^{c}$ Belgorod State University, 85 Pobeda Sq., Belgorod, 308015, Russia; e-mail: max_evstigneev@mail.ru; ${ }^{\mathrm{d}}$ Sevastopol State University, Crimea. Translated from Zhurnal Prikladnoi Spektroskopii, Vol. 82, No. 3, pp. 341-347, May-June, 2015. Original article submitted January 26, 2015. 

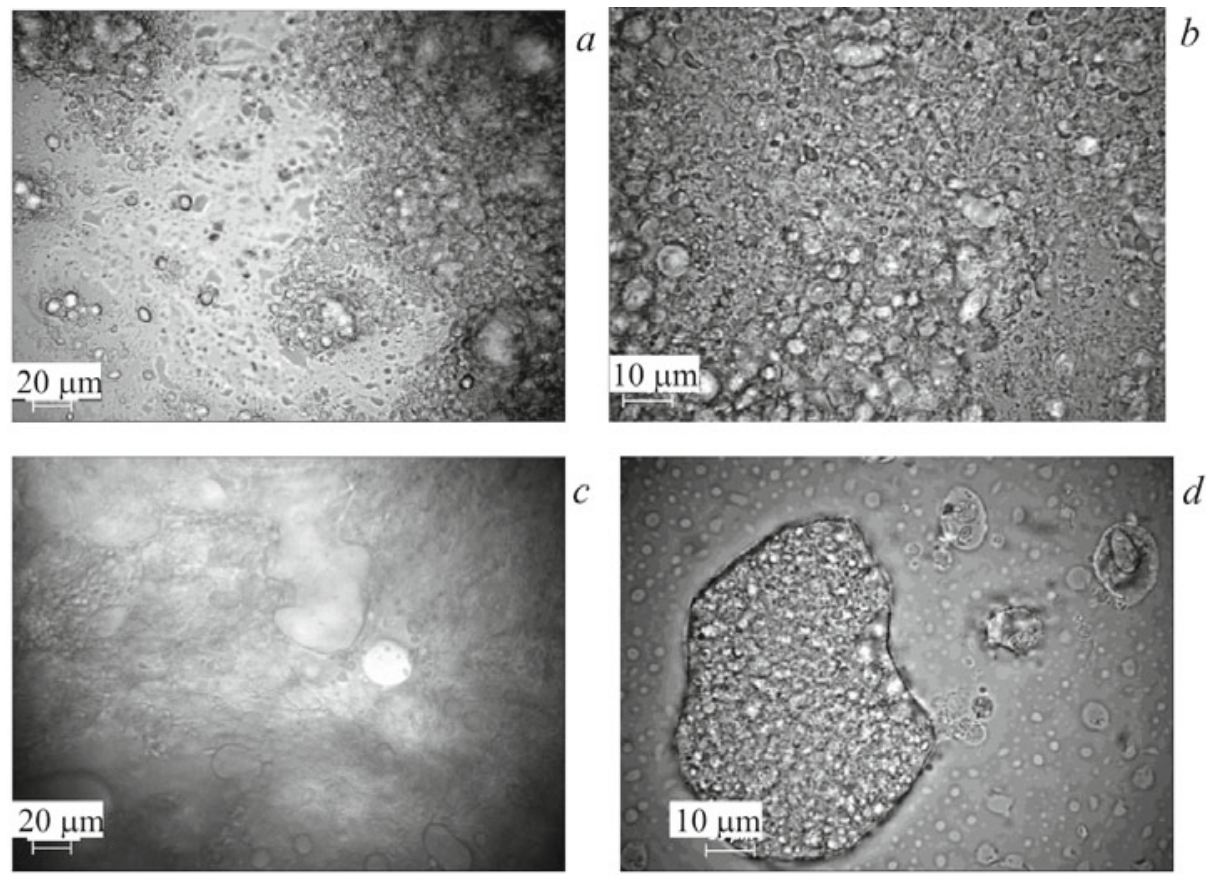

Fig. 1. Photomicrographs of milk mushroom symbiont for the sample containing water $(32 \mathrm{~g} / \mathrm{g})$ in air $(\mathrm{a}, \mathrm{b})$ with $h=32$ (a) and $16 \mathrm{~g} / \mathrm{g}$ (b) in addition to samples with $h=32 \mathrm{~g} / \mathrm{g}$ and added silicone [10 (c) or $60 \mathrm{~g} / \mathrm{g}$ (d)]; magnification $400 \times(a, c)$ and $1000 \times(b, d)$.

Photomicrographs of powders and emulsions were obtained on a Primo Star microscope (Carl Zeiss, Germany) at $400 \times$ and $1000 \times$ magnification using immersion. NMR spectra were recorded on a high-resolution NMR spectrometer (Varian, Mercury) at operating frequency $400 \mathrm{MHz}$. Eight 1- $\mu$ s 60-degree probe pulses at bandwidth $20 \mathrm{kHz}$ were used. The probe temperature was controlled by a Bruker VT-1000 thermal accessory to $\pm 1 \mathrm{~K}$. Resonance intensities were determined by measuring peak areas using a procedure to deconvolute the resonance into components assuming a Gaussian peak shape and optimizing the baseline and phase to an accuracy that was $<5 \%$ for well-resolved resonances and $\pm 10 \%$ for overlapping resonances. The concentration of unfreezing water was measured by heating samples that were cooled beforehand to $210 \mathrm{~K}$ in order to avoid supercooling of the water in the samples. Temperature dependences of the NMR resonance intensities were measured using an automated cycle (sample held at constant temperature for $9 \mathrm{~min}$; measurement time, $1 \mathrm{~min}$ ).

Chemical shifts in Tibetan milk mushroom samples were measured in $\mathrm{CDCl}_{3}$ or polydimethylsiloxane with the methyls taken as $0 \mathrm{ppm}$ relative to the TMS resonance. An external TMS standard was used for the sample without organic medium (a part of the working volume of the measurement tube was filled with air). The biomass for the NMR measurements was $0.15-0.30 \mathrm{~g}$.

Proton chemical shifts $\left(\delta_{\mathrm{H}}\right)$ were used as the main parameter determining the structure of the water H-bond network. It was assumed that water, in which each molecule is involved in four $\mathrm{H}$-bonds (two through protons and two through unshared $\mathrm{O}$ electron pairs), had chemical shift $\delta_{\mathrm{H}}=7 \mathrm{ppm}$ (as occurs in hexagonal ice) and weakly associated water (not involved in the formation of H-bonds as a proton donor), $\delta_{\mathrm{H}}=1.0-1.5 \mathrm{ppm}$ [4]. The Gibbs-Thompson equation that relates the radius of a spherical or cylindrical water cluster or domain $(R)$ to the freezing-point depression was used to determine the geometric dimensions of the adsorbed water clusters $[10,11]$ :

$$
\Delta T_{\mathrm{m}}=T_{\mathrm{m}}(R)-T_{\mathrm{m}, \infty}=2 \sigma_{\mathrm{SL}} T_{\mathrm{m}, \infty} / \Delta H_{\mathrm{f}} \rho R,
$$

where $T_{\mathrm{m}}(R)$ is the melting point of ice located in pores of radius $R ; T_{\mathrm{m}, \infty}$, the melting point of bulk ice; $\rho$, the solid-phase density; $\sigma_{\mathrm{SL}}$, the interaction energy of the solid with the liquid; and $\Delta H_{\mathrm{f}}$, the volumetric enthalpy of fusion. Equation (1) could be written for practical use as $\Delta T_{\mathrm{m}}=k / R$, in which $k \approx 50 \mathrm{~K} \cdot \mathrm{nm}$ for many heterogeneous systems containing water [10]. The procedure for taking the NMR measurements and the methods for determining the radii of the interfacial water clusters were described in detail [9]. Polyassociates with radii $R<2 \mathrm{~nm}$ were considered clusters; polyassociates of larger sizes, domains or nanodrops because they contained several thousand water molecules [8]. 
Free-energy changes due to effects from the limited space and the nature of the interface corresponded to freezing (thawing) of bound water. The differences from the bulk process decreased as the distance of the water layer from the surface increased. Bulk water froze at $273 \mathrm{~K}$. Water layers closer to the surface froze as the temperature was lowered (without considering supercooling). The following equation was valid for measuring the free energy of bound water (ice):

$$
\Delta G_{\text {ice }}=-0.036(273.15-T),
$$

where the numerical coefficient was related to the temperature coefficient of the Gibbs free-energy change for ice [4, 6]. The amount of strongly and weakly bound water and the thermodynamic characteristics of these layers could be calculated by determining the temperature dependence of the unfreezing water concentration $C_{\mathrm{uw}}(T)$ from the resonance intensity according to the published procedure [9].

The interfacial energy of water at the boundary with the solid particles or in its aqueous solutions was determined as the modulus of the total reduction of the water free energy that was due to the presence of the interface [4] using the formula:

$$
\gamma_{\mathrm{S}}=-K \int_{0}^{C_{\mathrm{uw}}^{\max }} \Delta G\left(C_{\mathrm{uw}}\right) d C_{\mathrm{uw}}
$$

where $C_{\mathrm{uw}}^{\max }$ was the total amount of unfreezing water at $273 \mathrm{~K}$.

The principal advantage of the procedure described above over solid-state NMR with magic-angle spinning was the ability to detect only those compounds for which the molecular motion was comparable with the molecular motion in the liquids. In this manner, resonances for only water and compounds soluble in the organic medium could be isolated from the total NMR resonance due to protons of biopolymers within the samples and the water bound to them. The resonance of the main part of the biopolymers was not observed because of the large difference in the transverse relaxation times of the liquids and the biopolymers in the viscous media.

Results and Discussion. Milk mushroom tissue is a heterogeneous material in which various cell types and the supracellular matrix can be identified. Figure 1 shows photomicrographs of symbiont containing water $(32 \mathrm{~g} / \mathrm{g})$ in air and with added silicone. PDMS-1000, despite its hydrophobicity, exhibits good affinity for milk mushroom. This could be related to the existence on its surface of not only centers that bind a large amount of water but also hydrophobic portions that can interact with the silicone through a van-der-Waals mechanism. In particular, it penetrates easily into the symbiont tissue, filling the voids in it (Fig. 1c), or forms microdrops that include small pieces of tissue (Fig. 1d). The silicone penetrating into the tissue is probably capable of diminishing the interactions among separate cells or cells and the intercellular matrix.

Figure 2 shows variable temperature PMR spectra of milk mushroom symbiont samples in air and also with added PDMS-1000. Addition of the silicone weakened the bonds in the symbiont supracellular structures and formed in the silicone a small amount of a stable suspension of cells or their aggregates. Water in the starting symbiont that was located in the cell protoplasm and was bound to the intercellular matrix appeared in the spectrum as a broad resonance, the intensity of which decreased as the temperature was lowered because of partial freezing. The proton chemical shifts increased from 5 ppm at $280 \mathrm{~K}$ to $6 \mathrm{ppm}$ at $220 \mathrm{~K}$. The water $\delta_{\mathrm{H}}$ value indicated that all bound water existed in a strongly associated state analogous to liquid water in which each water molecule was involved in forming two or three H-bonds. The chemical shift that was slightly greater than for liquid water $\left(\delta_{\mathrm{H}}=4.5-5 \mathrm{ppm}\right)$ suggested that this type of water was highly ordered. Partial dehydration of the symbiont had little effect on the shape of bound-water spectra (Fig. 2b and 2c). The appearance of fine structure in the spectra at $>270 \mathrm{~K}$ (Fig. 2b) may have been related to the heterogeneity of the studied sample. A resonance at $\delta_{\mathrm{H}}=1 \mathrm{ppm}$ that was probably due to weakly associated water (WAW) was also observed in spectra of the weakly hydrated sample (Fig. 2c) at $>265 \mathrm{~K}$.

The PDMS methyl resonances at $\delta_{\mathrm{H}}=0 \mathrm{ppm}$ appeared in the spectra with $30 \%$ silicone (Fig. 2e). The temperature range in which the water resonance was recorded narrowed markedly. This effect was enhanced as the fraction of silicone in the sample increased (Fig. 2d). Also, a WAW resonance appeared in the spectra near $\delta_{\mathrm{H}} \approx 1 \mathrm{ppm}$, which may have been due to WAW formed at the interface of the biomaterial with the hydrophobic PDMS medium [4].

Resonances of methyl and methylene protons of aliphatic fragments in cell-membrane phospholipids were expected in this same spectral range. However, the observed resonance could be assigned primarily to WAW because of the small amount of dry material in the cell mass and the relatively high intensity of the resonance, which corresponded to $3 \mathrm{~g}$ of proton-containing substance per $\mathrm{g}$ of dry cell mass. 

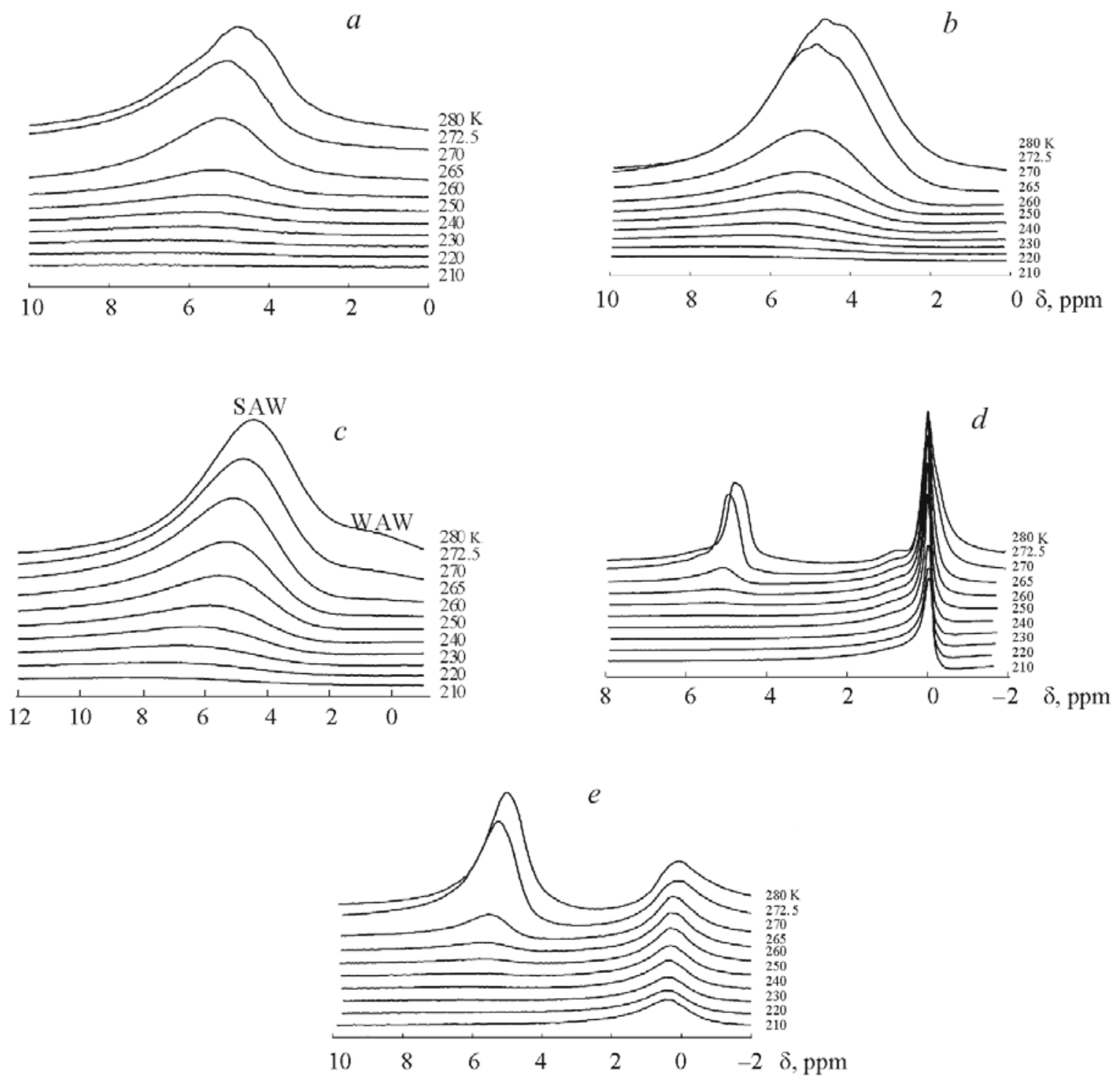

Fig. 2. Variable temperature PMR spectra of milk symbiont samples containing water [32 (a), 16 (b), and $0.3 \mathrm{~g} / \mathrm{g}(\mathrm{c})]$ in air and the sample with $32 \mathrm{~g} / \mathrm{g}$ and added PDMS-1000 [0.3 (d) and $2 \mathrm{~g} / \mathrm{g}(\mathrm{e})]$.

As a rule, polymers do not penetrate the cell membrane and are concentrated in the intercellular space or gaps between fibrils of the supracellular matrix. However, as was shown using yeast cells and rat liver tissue as examples [12], a mixture of a weakly polar organic solvent $\left(\mathrm{CHCl}_{3}\right)$ and trifluoroacetic acid (TFA) was capable of penetrating into the cells and affecting the state of the intracellular water. The $\mathrm{CHCl}_{3}$ probably made the phospholipid layer of the cell membranes permeable to acid molecules by dissolving in it. The protoplasm was an aqueous medium in which the cell formative elements, the gaps between which had submicron dimensions, could exist. Therefore, it could be thought that water in the cells (and also in the intercellular gaps) existed as nano-sized polyassociates, i.e., clusters or domains.

Figure 3a shows variable temperature PMR spectra of starting symbiont $(h=32 \mathrm{~g} / \mathrm{g})$ in $4 \mathrm{CDCl}_{3} / 1 \mathrm{TFA}$. Two groups of resonances belonging to strongly associated water (SAW) and WAW are distinguishable in the spectra. The SAW resonances were shifted to weak field (greater chemical shifts) owing to rapid proton-exchange between water molecules and TFA. The separate detection of several types of SAW clusters was due to slow exchange of water molecules within different clusters (domains). The different $\delta_{\mathrm{H}}$ values for resonances 1-3 indicated that TFA had different solubilities in SAW clusters with different structures or sizes. The smaller $\delta_{\mathrm{H}}$ was, the less soluble TFA was. Because the intensity of resonance 3 decreased more as the temperature was lowered, it was assumed that this resonance was due to relatively large water polyassociates. 

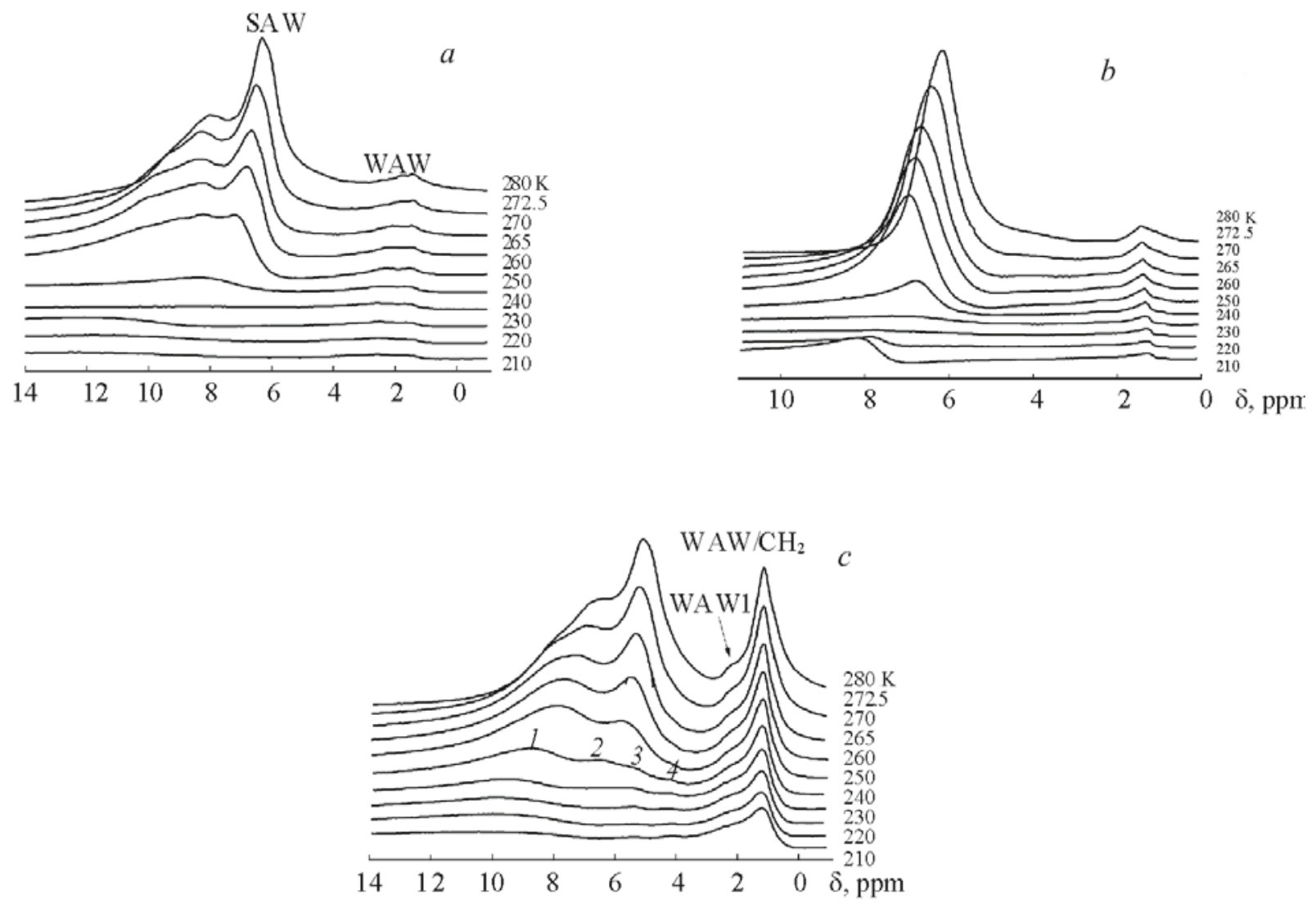

Fig. 3. Variable temperature PMR spectra of milk symbiont samples containing water in $\mathrm{CHCl}_{3}$ with added trifluoroacetic acid: $\mathrm{H}_{2} \mathrm{O}, 32 \mathrm{~g} / \mathrm{g} ; 4 \mathrm{CDCl}_{3} / 4 \mathrm{TFA}$ (a); $\mathrm{H}_{2} \mathrm{O}, 16 \mathrm{~g} / \mathrm{g} ; 4 \mathrm{CDCl}_{3} / 1 \mathrm{TFA}$ (b); $\mathrm{H}_{2} \mathrm{O}, 0.3 \mathrm{~g} / \mathrm{g}$; $8 \mathrm{CDCl}_{3} / 1 \mathrm{TFA}(\mathrm{c})$.

Considering that the chemical shift of the WAW resonance practically did not change in the presence of TFA, it was thought that this type of bound water did not dissolve TFA.

Partial dehydration of the symbiont (Fig. 3b) simplified the spectrum of unfreezing water. Only one SAW resonance was detected. Its chemical shift shifted to greater $\delta_{\mathrm{H}}$ values as the temperature was lowered. The dehydration was probably accompanied by a reduction in the linear dimensions of the cells (because the least strongly bound water was removed) and the approach of various types of water polyassociates, which caused the molecular exchange to accelerate. The differentiation of the various types of cluster structures in the symbiont sample was restored if the water content was decreased further ( $h=0.3 \mathrm{~g} / \mathrm{g}$, Fig. 3c). Moreover, resonance 4 that belonged to SAW that did not dissolve TFA and had a partially destroyed H-bond network appeared at $\delta_{\mathrm{H}}=4 \mathrm{ppm}$. Also, the intensity of the resonance at $\delta_{\mathrm{H}}=1 \mathrm{ppm}$, which could be assigned to both WAW and $\mathrm{CH}_{2}$ groups of cell-membrane phospholipids, increased significantly (compare Fig. 3c with Fig. 3a and 3b). In addition, a resonance for which the intensity increased with decreasing temperature was recorded at $\delta_{\mathrm{H}}=2 \mathrm{ppm}$. One of the WAW species involving molecules of the hydrophobic medium that did not dissolve TFA was probably stabilized.

Figure $4 \mathrm{a}$ shows the concentration of unfreezing water as a function of temperature; Fig. 4b, the radius size distribution of bound water clusters (domains) that was calculated using the Gibbs-Thompson equation [Eq. (1)]. Table 1 presents the characteristics of the water layers and the interphase energy of the symbiont in aqueous medium and with added PDMS-1000.

According to Fig. 4a, the cell mass bound a very large amount of water, which reached $32 \mathrm{~g}$ per $\mathrm{g}$ of dry cell mass. The functions $C_{\mathrm{uw}}(T)$ showed an inflection at $260 \mathrm{~K}$ that divided them into two parts corresponding to strongly bound (SBW) and weakly bound (WBW) water [4, 6]. A large part of the water retained by the symbiont was WBW (froze at $>260 \mathrm{~K}$ ). The fraction of SBW increased with decreasing sample (in air) hydration. The interphase energy, which determined the total reduction of the water free energy due to its interaction with the interfaces, decreased in proportion to the sample hydration. The presence of silicone caused $\Delta G_{\max }$, which determined the free-energy decrease in the water layer bounding the surface, to decrease. Hence, PDMS-1000 weakened the interaction of water with biopolymer structures of the cells and supracellular 

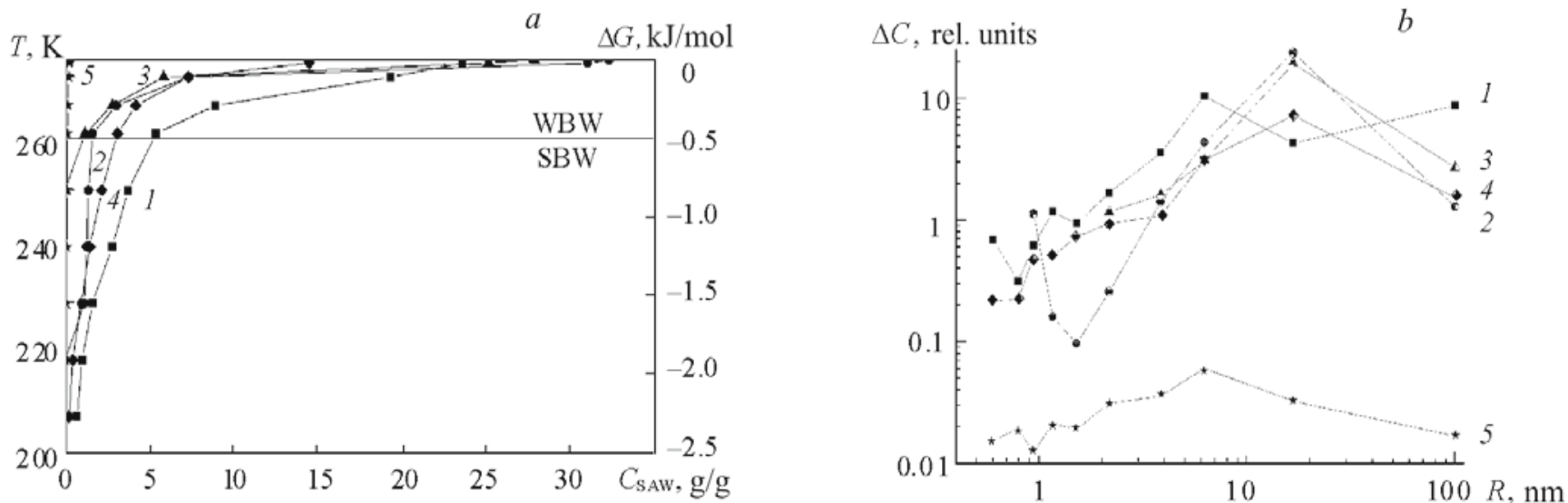

Fig. 4. Concentration change of unfreezing water as a function of temperature (Gibbs free-energy change) (a) and radius size distribution of clusters (domains) of unfreezing water (b) for milk symbiont with hydration $h=32$ g/g, air (1); 32 g/g, PDMS 0.3/1 (2); 29 g/g, PDMS 2/1 (3); 16 g/g, air (4); and 0.25 g/g, air (5).

TABLE 1. Characteristics of Unfreezing Water Layers in Milk Mushroom Symbiont with Various Hydrations

\begin{tabular}{|c|c|c|c|c|c|}
\hline$h, \mathrm{~g} / \mathrm{g}$ & Medium & $C_{\mathrm{uw}}^{\mathrm{s}}, \mathrm{g} / \mathrm{g}$ & $C_{\mathrm{uw}}^{\mathrm{W}}, \mathrm{g} / \mathrm{g}$ & $\Delta G_{\max }, \mathrm{kJ} / \mathrm{mole}$ & -4 \\
\hline 32 & air & 5.5 & 26.5 & -3.3 & 450 \\
16 & air & 3.2 & 12.8 & -3.6 & 472 \\
0.3 & air & 0.15 & 0.05 & -2.25 & 572 \\
32 & PDMS 0.3/1 & 1.5 & 30.5 & -1.2 & 435 \\
32 & PDMS 2/1 & 1 & 31 & \\
\hline
\end{tabular}

matrix. The decreased effectiveness of the intercellular bonds because of the interaction with liquid silicone caused the amount of SBW to decrease from 5.5 to $1 \mathrm{~g} / \mathrm{g}$ (Table 1 ).

Substantial differences were also observed in the radius size distributions of intracellular water clusters (Fig. 4b). The contributions of water clusters and domains with $R<10 \mathrm{~nm}$ and $R=100 \mathrm{~nm}$ were elevated in the starting cell mass. The contribution of water domains with $R=100 \mathrm{~nm}$ decreased as the water content decreased. The presence of silicone in the symbiont caused clusters with $R<1 \mathrm{~nm}$ (PDMS $0.3 \mathrm{~g} / \mathrm{g}$ ) and $R<2 \mathrm{~nm}$ (PDMS $2 \mathrm{~g} / \mathrm{g}$ ) to disappear.

Conclusions. PMR spectroscopy showed that the maximum hydration of milk symbiont was $32 \mathrm{~g}$ per $\mathrm{g}$ of dry substance with greater than $5 \mathrm{~g} / \mathrm{g}$ of water being SBW that froze at $<260 \mathrm{~K}$. Water bound by the symbiont existed as clusters and domains of radii $0.6-100 \mathrm{~nm}$. The presence of a hydrophobic medium or partial dehydration could lead to the formation of a significant amount of WAW. Bound water was differentiated into a system of polyassociates that bound different amounts of TFA in a mixed organic medium consisting of eight parts $\mathrm{CHCl}_{3}$ and one part TFA. The spectra exhibited up to six water resonances, among which WAW and several forms of SAW did not dissolve TFA. The silicone medium decreased considerably the interaction of bound water with the internal interfaces.

\section{REFERENCES}

1. A. V. Oleskin, J. Basic Microbiol., 34, 425-439 (1994).

2. J. W. Costerton, in: Abstracts of Beijerinck Centennial "Microbial Physiology and Gene Regulation: Emerging Principles and Applications," Delft Univ. Press, (1995), pp. 20-21.

3. B. Kasemo, Surf. Sci., 500, 656-677 (2002).

4. V. M. Gun'ko, V. V. Turov, V. M. Bogatyrev, V. I. Zarko, R. Leboda, E. V. Goncharuk, A. A. Novza, A. V. Turov, and A. A. Chuiko, Adv. Colloid Interface Sci., 118, 125-172 (2005).

5. J. Vicha, M. Malon, P. Vesela, O. Humpa, M. Strnad, and R. Marek, Magn. Reson. Chem., 48, 318-322 (2010). 
6. V. V. Turov, V. F. Chehun, V. N. Barvinchenko, T. V. Krupskaya, Yu. I. Prylutskyy, U. Ritter, and P. Scharff, J. Mater. Sci.: Mater. Med., 22, 525-532 (2011).

7. T. Esatbeyoglu B. Jaschok-Kentner, V. Wray, and P. Winterhalter, J. Agric. Food Chem., 59, 62-69 (2011).

8. V. M. Gun'ko and V. V. Turov, Nuclear Magnetic Resonance Studies of Interfacial Phenomena, Taylor \& Francis, New York (2013).

9. V. V. Turov, Yu. I. Prylutskyy, A. P. Ugnivenko, V. N. Barvinchenko, T. V. Krupskaya, N. G. Tsierkezos, and U. Ritter, Low Temp. Phys., 40, 309-316 (2014).

10. D. W. Aksnes and L. Kimtys, Solid State Nucl. Magn. Reson., 25, 146-163 (2004).

11. O. V. Petrov and I. Furo, Prog. Nucl. Magn. Reson. Spectrosc., 54, 97-122 (2009).

12. V. M. Gun'ko, T. V. Krupska, V. M. Barvinchenko, and V. V. Turov, Chem. Phys. Technol. Surf., 3, 359-374 (2012). 